\title{
NARRATIVAS E RECONSTRUÇÕES DE SI: NO MAR O VIVER, NA MARÉ O FAZER, NA HISTÓRIA O SABER
}

Emerson Augusto Medeiros, Ana Lucia Aguiar Lopes Leandro e Helena Perpétua de Aguiar Ferreira

E-mail: emerson.au@hotmail.com ${ }^{1}$

Artigo submetido em maio/2013 e aceito em dezembro/2013

\section{RESUMO}

Este trabalho discute sobre os saberes de pessoas que construíram suas vidas em articulação e interação com o mar. O saberes dos povos do mar são saberes exclusivos de indivíduos que tem sua trajetória fundamentada na prática com a água e a maré. A pertinência científica e social deste trabalho está ancorada no sentido de percebermos que a educação atual caminha valorando os conhecimentos oriundos das ciências, pouco se dando crédito aos saberes das pessoas ditas comuns. Em diálogos construídos com pescadores e marisqueiros e nas narrativas dos sujeitos pesquisados alicerçamos nosso estudo. Os autores que compõem este trabalho tais como: Freire (2005), Santos (2008) e Gohn (2010) discutem aspectos importantes para a compreensão e reflexão do estudo. Nas narrativas dos atores e autores da pesquisa percebemos que seus saberes estão ancorados em sua cultura, servindo para construção de suas ações e práticas. Pescar, mariscar, viver no mar são algumas atividades e comportamentos que reforçam a identidade desses sujeitos. Compreendemos que a experiência de vida no mar é fator decisivo na formação das populações do mar. Compromisso com a vida, participativos no trabalho os sujeitos da pesquisa, validam seus saberes como teia que conduz sua existência, e os tornam sujeitos conscientes no mundo.

PALAVRAS-CHAVE: Saberes. Povos do Mar. Narrativas. Educação.

\section{NARRATIVES AND RECONSTRUCTIONS OF YOURSELF: LIVING IN THE SEA, THE TIDE TO DO IN HISTORY TO KNOW}

\begin{abstract}
This paper discusses the knowledge of people who have built their lives in liaison and interaction with the sea. The knowledge of the Sea People are unique individuals who have knowledge of their grounded in practice with the water and the tide trajectory. The scientific and social relevance of this work is anchored in order to realize that the current education walks valuing the knowledge from the sciences, giving little credit to the common knowledge of such persons. In dialogs built with fishermen and shellfish and narratives of the individuals begin our study. The authors that make this work such as Freire (2005), Santos (2008) and Gohn (2010) discuss important aspects for understanding and
\end{abstract}

reflection of the study. In the narratives of the actors and authors of the research realized that their knowledge are grounded in their culture, serving for the construction of their actions and practices. Fishing, shellfishing, live in the sea are some activities and behaviors that reinforce the identity of these individuals. We understand that the experience of life at sea is a decisive factor in the formation of populations of the sea. Commitments to life, participating in the work the research subjects, validate their knowledge as a web that leads its existence, and make them aware subjects in the world

KEYWORDS: Knowledge. Peoples of the Sea Narratives. Education. 


\section{NARRATIVAS E RECONSTRUÇÕES DE SI: NO MAR O VIVER, NA MARÉ O FAZER, NA HISTÓRIA O SABER}

\section{INTRODUÇÃO}

"Mar", "água", "vento", "Sol”, "areia", "pescar", "mariscar", "nadar", "maré", "onda”, "praia”, "peixe”, "caranguejo", "barco", "marisco", "lagosta”, "rede”, "jangada"... O que essas palavras representam?

Os povos do/no mar carregam uma herança cultural que não referencia apenas o contato do homem com a natureza, do homem com a água. A maré é mais que a maré, a praia é mais que a praia, esses elementos são lócus nos quais o pescador constrói sua identidade e a história de seus povos.

Essas palavras sinalizam o universo cultural e simbólico que se entrelaça a alma, ao corpo, as mãos do Ser pescador; palavras que assumem o enredo social e cultural de homens e mulheres, crianças, jovens e idosos considerados guardiões de saberes plurais que se formam em contato direto com a natureza, com água e o mar; palavras operadoras de uma totalidade existencial, conjugando sentidos diversos, articulando sentimentos e ações.

Nesse contexto, o presente trabalho se insere objetivando refletir acerca dos saberes de sujeitos que construíram sua formação galgada nas raízes da experiência, no saber-fazer, no tete a tete cotidiano, vivendo, conhecendo, aprendendo, crescendo com perdas e ganhos, dores e alegrias, amor e ardor.

Para Santos (2010) no decorrer da história civilizacional a ciência instituiu e consagrou o saber acadêmico como um tradutor privilegiado das verdades e concepções do mundo e dos fenômenos cósmicos. Esse saber por se estabelecer dentro de uma esfera epistemológica, estando permeado por características objetivas, quantitativamente mensuráveis ou qualitativamente observáveis é o único capaz de trazer reflexões acerca da natureza e do humano.

O saber do homem dito comum é visto, como um saber imprudente para o desenvolvimento vital e planetário, pois se apresenta destituído do rigor lógico, estando impregnado de impressões psicológicas e de subjetividades que diminuem sua veracidade constitutiva.

É a partir dessa perspectiva que tomamos aqui as narrativas e as histórias de vidas de homens do mar que assumem no estudo o lugar de narradores. Narradores porque informam a vida, dizem de saberes que referenciam e perpetuam a especificidade do viver do/no mar.

Esses narradores são uma marisqueira da cidade de Tibau/RN e um pescador da comunidade de Redonda, distrito do município de Icapui/CE ${ }^{1}$, cujas vidas se fizeram na lida com o mar, com a maré, pescando e mariscando, sentido cotidianamente o sabor e o saber da cultura

\footnotetext{
${ }^{1}$ Destacamos que os narradores falaram sobre si e sobre suas histórias de vida em diálogos construídos em duas aulas de campo, na disciplina Movimentos Sociais e Educação Popular, do Mestrado em Educação, da Universidade do Estado do Rio Grande do Norte - UERN.
}

HOLOS, Ano 29, Vol. 6 
através da luta de todos os dias, saber e sabor abrangentes que abarcam diversas dimensões da vida.

A escolha pelos sujeitos da pesquisa se justifica pelo fato de sua interligação com o mar e suas nuances. Ao participarmos de momentos em seus lugares de vida e buscando narrativas de sujeitos que contemplassem o propositado no estudo, ouvindo homens e mulheres do mar das duas cidades, fomos inseridos a encontrar os dois sujeitos pelo amplo tempo de vida junto à existência com sua profissão no mar e nas águas. $O$ tempo de experiência junto às atividades no mar foi o principal critério de seleção, bem como suas disponibilidades e abertura para participar do estudo, para descortinar suas histórias de vida e trajetórias, suas lembranças e memórias.

Acrescentamos que o estudo é de natureza qualitativa. Essa abordagem de pesquisa, segundo Minayo (2007) possibilita uma relação dinâmica entre o mundo real e o sujeito, isto é, um vínculo indissociável entre o mundo objetivo e a subjetividade humana que não pode ser traduzido em números.

No artigo conheceremos através das narrativas alguns dos saberes fundantes dos povos do mar, algumas experiências formativas. A memória reconstruindo uma trajetória trará o vivido, o sentido, o labor, a vida do pescador com todo o repertório que se articula a sua existência e ao conteúdo histórico de seu povo.

\section{HISTÓRIAS DE VIDA E CONHECIMENTO DE SI: CONTANDO A VIDA, NARRANDO A FORMAÇÃO.}

"Nós fazemos História com o povo"

(Pescador, comunidade de Redonda, Icapui/CE)

Ser pescador supõe uma pluralidade de conhecimentos. Não se trata de conhecimentos únicos, mas saberes múltiplos que se estabelecem na experiência vivenciada no decorrer da vida, saberes que não estão relacionados ao nível de escolaridade, mas constituem-se na relação familiar, no contato com a comunidade, com a maré e o mar, saberes das águas, passados de geração para geração, saberes sustentáveis com base na diversidade do lugar.

Não se faz pescador, não se torna pescador de um dia e de um momento para outro. Vaise sendo pescador, ao longo da história e da vida, em interação com a natureza, com o mar, com os peixes, com a água, com a família. Nesse sentido, pressupõe-se a convivência de uma vida inteira.

As histórias de vida dos pescadores falam de uma existencialidade, narram sabedoria, falam do mar. Há um conhecimento de vida, rico de saberes, construído ao observar os horários das marés, ao observar a natureza, o movimento das águas, ao ouvir o vento, ele advém na pesca cotidiana, na construção da rede, do arpão e da tarrafa para pegar o peixe.

Como é sabido, Freire (2005) ao dissertar sobre o saber infere que não há saber sem uma relação, com o outro, com o mundo, consigo próprio. O homem, ser ontológico, axiológico e cultural aprende e humaniza-se no e com o mundo, através do diálogo, esse não se faz 
unicamente na palavra, mas na práxis (ação e reflexão), em uma ação interativa de criação e recriação, na experiência, no contato com a vida, com a própria história.

O pescador nesse mundo faz-se homem, torna-se sujeito existente, no perigo das fortes ondas, no sol queimante, nas águas salgadas do oceano. Narrativas, (auto) biografias informam sobre um saber plural da vida e na vida, sobre um saber heterogêneo que historiciza e ao mesmo tempo singulariza a humanidade terrestre.

As mulheres marisqueiras sobrevivem do marisco, elas vão para a praia, muitas usam protetor solar, outras não usam nada. [...] Minha mãe é marisqueira e minha avó foi também, isso vão passando de uma para outra. [...] Elas dividem o que tem e uma ajuda à outra. Quando uma tem muita encomenda e a outra não tem nada, ela sede e vende o da outra e dividem. [...] O tempo de mariscar é no inverno. Já ouve tempo em que muitas conseguiam muito marisco, hoje está mais fraco. [...] Não tem uma técnica não para mariscar é ir para a praia, quando a maré está baixa. As marisqueiras sabem o horário de pegar os mariscos. [...] Tem época que a praia está cheia de mulheres mariscando, muitas delas só tiram o sustento disso (Entrevista feita com uma Marisqueira², Tibau/RN, 2012).

Há dois tipos de lagosta. Tem a verde e a vermelha. [...] aprendemos isso no mar. [...] desde menino, eles aprendem a pescar. [...] vivem no mar com os pais. [...] Já ouve tempo em que os pescadores aqui pescavam muito, antigamente os viveiros saiam cheio de peixe, agora a pesca está muito fraca. [...] Há a pesca predatória, mais nós aqui só trabalhamos com barcos permitidos. A associação tem incentivado a fazer esse trabalho e busca recursos para ajudar aos pescadores daqui. [...] Os homens passam vários dias no mar, levam comida e também se alimentam do que pescam. [...] poucas vezes acontecem acidentes se eles trabalham com o barco certo, mas quando eles praticam a pesca predatória sempre acontecem acidentes, muitos homens aqui têm cicatrizes no corpo. [...] Tem os que pescam lagosta [...] tem o período certo para pescar a lagosta, e quando a época é suspensa eles recebem o seguro, os pescadores não tem isso. (Entrevista feita com um Pescador, Comunidade de Redonda, Icapui/CE, 2012)

As histórias dos povos do mar envolvem todo um encanto e bravura, são transmitidas e reconstruídas em cada geração, dá continuidade à especificidade de um povo. Nelas a natureza se apresenta e fornece muitas vezes os próprios instrumentos para a construção dos materiais necessários à pesca, seja para o barco ou para o viveiro que serve para capturar o peixe.

Há criatividade, luta, organização, persistência, garra, alteridade, participação na formação do sujeito e homem do mar, homem das águas, Ser pescador. Da infância à vida adulta aprendem em comunhão; no contato direto com a água, enterram seu umbigo na areia da praia e nela apreendem uma identidade, que se evidencia na voz, no olhar, no modo de conceber a vida.

Nesse planeta água, nesse viver mar, há saberes que a ciência no dizer de Santos (2008, p. 61) renega e não considera como pertinente à condição planetária atual.

\footnotetext{
${ }^{2}$ Objetivando guardar a identidade dos participantes do estudo, optamos por não apresentar nomes e imagens acerca do trabalho construído com os pescadores.
} 
Sendo um modelo global, a nova racionalidade científica é também um modelo totalitário, na medida em que nega o carácter racional a todas as formas de conhecimento que não se pautarem pelos princípios epistemológicos e pelas suas regras sistemáticas.

À luz da ciência moderna o saber do homem dito comum é tão só extensão e movimento, é passivo, ideológico, artificial e condutivo. Não são creditados os conhecimentos, a sabedoria e a integração da vida terrestre, da formação do sujeito com a natureza.

Corroboramos com Santos (2008, p.85), a ideia de que "o saber da vida aprendido na construção do conhecimento edificado na vivência deve ser afirmado como conhecimento prudente", pois é na relação coletiva e social que nos formamos como homens críticos e conscientes a respeito da vida e da nossa condição de existência.

Os dizeres que ecoam na voz e se apresentam na narrativa da Marisqueira, participante do estudo, resgatam a memória dos povos que vivem do/no mar, versam sobre um modo sustentável e singular de viver, trazem a cultura local, apresentam uma originalidade no aprender e também no saber.

Para a Marisqueira, há um tempo certo de se praticar o mariscar, há união e cooperação entre os que trabalham e sobrevivem dessa atividade, há um conhecimento de si que se referencia na consciência e no reconhecimento acerca das mudanças ocorridas no meio natural em que vive, que emerge na espontaneidade e autenticidade do fazer-mariscar. Contudo, sua fala também conta sobre as dificuldades imposta às vidas de sujeitos que esperam o tempo da natureza para se tirar o sustento e o alimento.

O pescador, ator e autor no estudo, diz de um coletivo que aprende no mar, de menino a homem. Ele narra tempos de abundâncias em que o peixe povoava as redes, ele informa saberes construídos na observação das águas, nas cores do mundo presentes no fundo do mar. Suas falas evidencia também a pesca predatória como um problema que os homens pescadores enfrentam no momento e o medo das guerras do mar $^{3}$.

Na entonação de sua voz, percebe-se a preocupação com a comunidade, a escassez do peixe traz angústia, mostra transformações ambientais que levam muitos pescadores a buscarem práticas prejudiciais à natureza. É patente ainda, que os problemas vividos pelo grupo encontram apoio na organização do coletivo que se faz na Associação de Pescadores existente na comunidade.

Gohn (2010) em sua obra "Movimentos Sociais e Educação" tece que muitas das conquistas presentes no bojo social de nosso país desenrolaram-se no seio de associações, sindicatos e movimentos sociais. Essa autora compreende que as transformações ocorridas no processo histórico do Brasil foram configurando cenários em que o direito à cidadania tornou-se a principal reivindicação feita nas lutas construídas.

\footnotetext{
${ }^{3}$ O pescador em um momento da entrevista utilizou o termo "guerras no mar", exemplificando os problemas com pescadores piratas, entendidos, como aqueles que praticam a pesca predatória.
} 
O homem do/no mar busca sua cidadania e mais que isso, sua existência, seu direito a existir considerando a essência de seu povo, fazendo barcos e canoas, pescando e mariscando, conhecendo espaços diferentes, horizontes azuis e vibrantes (o mar), correndo na praia, banhando-se na maré, alimentando-se do sol, bebendo de sua cultura, de seus valores, de seus costumes e de seu mundo-mar. É no ato de cheirar, tocar, degustar, observar, examinar, sentir, ouvir e ver esse mundo que o pescador aprende a conhecer seu próprio saber, convertendo-se em conhecimento de si, da vida.

As narrativas expostas estão permeadas de situações vivenciadas pelos pescadores do estudo, dizem da formação identitária e subjetiva de povos do mar. Elas mostram experiências refletidas, pois reordenam saberes e conhecimentos do grupo.

Concordamos com Momberger ${ }^{4}$ (2008, p.97) o pensamento de que "tudo que é narrado e partilhado pode se constituir em elemento politizador de novas sínteses criativas e em elos que ligam os sujeitos entre si". Entendemos que experiência e narrativa são pares indissociáveis do saber e da cultura. Nesse sentido, contar a vida é narrar a formação. Na história de vida contada descortinamos o "eu", falamos do sujeito e de sujeitos que se agregam ao itinerário explorado.

\section{NARRAR PARA CONSTRUIR EDUCAÇÃO: COMPARTILHANDO EXPERIÊNCIAS}

O homem aprende na rua, na escola, no mato, no mar, na igreja, na casa do vizinho, no quintal, na praça, no clube, na praia... Aprende porque é um ser social, porque se faz no diálogo, com outro e com o próprio mundo (FREIRE, 2005).

Brandão (1995) em sua obra "O que é educação" alude que o conceito de Educação deve transcender ao ato e ao fazer pedagógico que acontece dentro de uma instituição de ensino. Para esse autor, não podemos dizer que existe apenas uma educação específica, mas sim "Educações" . Educações porque estamos a todo o momento aprendendo, conhecendo e formando saberes e nos formando socialmente.

O pescador aprende no mar, na praia, no barco, no ciclo cultural em que vive, com seus companheiros de trabalho, com seus pais e filhos. Nas marés da vida, o pescador educa e faz educação. No entanto, é válido acrescentar que ele precisa de espaços para sistematizar e articular o conhecimento que construiu na vida, bem como ampliar os conhecimentos produzidos pela sociedade, na qual vivemos.

Nessa discussão, o espaço escolar se insere como peça fundamental para transformar as experiências individuais em experiências coletivas, bem como para construir o diálogo e o

\footnotetext{
${ }^{4}$ Para aprofundar diálogos acerca do trabalho com as narrativas ver: BUENO, Belmira O.; CATANI, Denice B.; SOUSA, Cynthia Pereira (Orgs). A vida e o ofício dos professores - formação contínua, autobiografia e pesquisa em colaboração. São Paulo: Escrituras Editora, 1998.

${ }^{5}$ Para uma discussão maior acerca do conceito de Educação ver: GOHN, Maria da Glória. Educação Não Forma e Cultura Política. São Paulo: Cortez, 2011. e também: LIBÂNEO, C. Pedagogia e Pedagogos Para Quê? São Paulo: Loyola, 2010.
} 
entrelaçamento acerca dos saberes ditos comuns como os saberes construídos pela comunidade científica (academia).

Reforçamos que se defendemos um ideário transformador de educação que possa contribuir para a formação plena do indivíduo é preciso como diz Santos (2008, p.112), "valorar a experiência do sujeito", não dissociando o homem da natureza, o homem de sua cultura. As narrativas abaixo falam de experiências positivas e negativas construídas pelos povos do mar, experiências que servem de exemplo para pensarmos a educação como ponte para formação e conscientização do homem no planeta. Elas expõem de maneira direta vivências de um coletivo, tratando da luta pelo direita a uma educação para e na própria vida.

$\mathrm{Na}$ associação conseguimos montar alguns grupos, tem o dos jovens, o $\mathrm{AJA}^{6}$, tem o da pesca e o da aquicultura. Tem o das mulheres. [...] temos obtido sucesso, há muito envolvimento e participação do pessoal daqui [...]. Os meninos aprendem o que fazer né? Com a ajuda de alguns órgãos a associação tem adquirido vários cursos, e muita gente vem. [...] A tecnologia chega e não ficamos distante. [...] Apesar disso acho que seria muito importante investimentos, não precisa só ensinar o povo a fazer, temos que ter recursos, se não for assim pouco adianta. [...] A comunidade tem crescido, é preciso acompanhar isso. [...] O pescador não tem mais tanta facilidade para pescar, antigamente os homens iam com os barcos e voltavam cheios, como eu já disse. [...] é preciso investir na educação e também na comunidade. (Entrevista feita com o pescador, comunidade de Redonda, Icapui/CE, 2012).

Quando assumi a presidência da colônia em 1994 as coisas eram muito difíceis. Desde lá venho lutando pelos pescadores e marisqueiros daqui. [...] Temos conseguido cursos para o pessoal, mas no momento a colônia não tem. A briga com o governo é de tempos. [...] Conseguimos também o direito do seguro da pesca $^{7}$. [...] O que venho tentando conseguir é o prédio da colônia. Faz tempo que vemos batalhando. [...] Fazemos reuniões, e não desistimos. [...] Há uma preocupação grande também dos pescadores com a educação de seus filhos, alguns até dizem que não querem seus filhos sendo pescadores. Olhe a vida do pescador é linda, linda, mais é sofrida. A educação do pescador é o mar, ele aprende pescando, na maré, mais é bonita demais. [...] levo muitos deles para se aposentar, tem alguns que arrumam empregos em firmas, mas eu digo mesmo, não manchem sua carteira (Entrevista feita com uma Marisqueira, Tibau/RN, 2012)

Freire (2005) decreta sobre a importância de construir uma educação, na qual os sujeitos sejam considerados como seres históricos e sociais, compreendendo a necessidade de conhecer sua origem e seu contexto de vida, garantindo a inclusão de seus saberes, como indispensáveis à sua libertação.

\footnotetext{
${ }^{6}$ AJA é o nome do grupo de Jovens dos filhos de pescadores da comunidade de Redonda, Icapui/CE.

${ }^{7}$ O seguro da pesca são recursos (salários) que o pescador recebe no período que não é permitido pescar, contudo, esse direito é dado somente aos pescadores de lagosta.
} 
Os saberes dos povos do mar são referenciados e advém de sua identidade cultural. Esse mundo-mar informa suas práticas. Eles mechem com a vida, atiça seus moradores, promovem reuniões, fazem refletir sobre sua condição social.

As narrativas descritas mostram a luta pelo direito à dignidade, incluindo nesse sentido a educação, luta que vem sendo travada e vivida pelos pescadores autores e atores do estudo. Eles tiram forças de seu enraizamento local, de sua participação no desenvolvimento dos espaços em que habitam.

A Marisqueira tece sobre dificuldades em conseguir um local permanente para a Colônia, na qual é presidente. É diante dessas barreiras e na luta cotidiana que os povos do mar conseguem construir seus modelos específicos de reivindicação. Ela fala ainda da busca pela inclusão e pelo reconhecimento desse coletivo. Apesar das conquistas já realizadas, percebe-se em sua narrativa a persistência e o engajamento no trabalho, o qual desenvolve; o não enfraquecimento na vida.

A educação do pescador na voz da Marisqueira aparece interligada à vivência no mar, porém, fica patente em sua fala que alguns pescadores se preocupam com a educação dos filhos, com seus futuros. Não desejam que seus filhos tenham a mesma vida e educação que eles.

Freire (2005) lembra que na educação humana a prática da liberdade só encontrará adequada expressão numa pedagogia em que o oprimido tenha condições de reflexivamente, descobrir-se e conquistar-se como sujeito de sua própria destinação histórica.

Assim, a educação dos povos do mar deve ser aquela que não concebe seus sujeitos como "vasilhas" para receberem saberes, mas tendo como base a aprendizagem ao longo da vida ${ }^{8}$.

O pescador participante da pesquisa dá ênfase em sua narrativa ao trabalho vivido na associação, na qual é membro. A organização do grupo é uma ferramenta e também um rico saber que tem possibilitado conquistas de objetivos definidos pela comunidade. Para os povos do mar é necessário além da educação, propostas e projetos que ajudem no desenvolvimento das populações que vivem do/no mar.

Como bem reforçado na voz do pescador, não basta que as populações estejam inseridas no discurso social, é preciso criar mecanismos e meios de desenvolvimento, que tragam qualidade vital. Os homens do/no mar vivem, crescem, fazem-se homens, fazem-se história na história da humanidade.

As narrativas contam à sociedade saberes de homens comuns, reconstruções humanas, experiências terrestres, tratam do mar. Desejamos que os ditos e os escritos nesse trabalho sirvam de iniciativas e reflexões aos que leem para pensarem em uma educação plural/singular aos povos do mar. Uma educação galgada na vida e na história do sujeito.

\footnotetext{
${ }^{8}$ Peter Alheit e Bettina Dausien na referência que segue, aprofundam o diálogo sobre a aprendizagem ao longo da vida: ALHEIT, Peter. DAUSIEN, Bettina. Processo de Formação e Aprendizagem ao Longo da Vida. Revista Educação e Pesquisa. São Paulo: Janeiro-Abril. 2006, Vol 32. Número. 001. P. 177-197.
} 


\section{CONSIDERAÇÕES DE UMA TRAJETÓRIA...}

Escrever sobre um trabalho significativo para quem os construiu não é tarefa fácil. As palavras somem, migram para lugares fora do pensamento. Elas se tornam raras, se inibem pela grandeza do vivido e do sentido.

O trabalho construído acerca dos saberes e das histórias dos povos do mar tratam não apenas de ciência, ele traduz a vida, a existência de um grande coletivo de pessoas, que sentem todos os dias o sabor do viver.

Nesse estudo, acreditamos que a emoção que permeia o ser homem em sua esfera vital, apareceu esboçando a simplicidade, o querer conhecer. Ela inquieta a ciência, que se vê no direito e no fazer vida. Inquieta porque ensina e forma, faz sentir.

Contudo, não buscaremos aprofundar diálogos, você leitor, sinta e veja esse pequeno momento vivido; não traremos interpretações, acreditamos que ela se faz na construção, no olhar de procura. Assim sendo, conheça interprete e reflita acerca de cada linha, em cada escrito, inquiete-se e busque conhecer, corroboramos com Freire, o qual diz que o homem se faz homem na procura.

\section{REFERÊNCIAS:}

BRANDÃO, Carlos Rodrigues. O que é Educação. 33. Ed. São Paulo: Brasiliense, 1995.

DELORY-MOMBEGER, Christine. Biografia e Educação: Figuras do indivíduo projeto. Tradução de Maria da Conceição Passegi. Natal - RN: EDUFRN, 2008.

FREIRE, Paulo. Pedagogia do Oprimido. 46. Ed. Rio de Janeiro: Paz e terra, 2005.

SANTOS, Boaventura de Souza. A crítica da razão indolente contra o desperdício da experiência. São Paulo: Cortez, 2008.

GOHN, Maria da Glória. Movimentos Sociais e Educação. São Paulo: Cortez, 2010.

MARISQUEIRA. Entrevista. [março 2013]. Entrevistadores Emerson Augusto de Medeiros e Ana Lúcia Aguiar Lopes Leandro. Tibau/RN, 2013. 1 (um) artigo. Rádio Gravador (123 min).

MINAYO, Maria Cecília de Souza (Org.). Pesquisa Social: Teoria, Método e Criatividade. 26a ed. Petrópolis, RJ: Vozes, 2007.

PESCADOR. Entrevista. [março 2013]. Entrevistadores Emerson Augusto de Medeiros e Ana Lúcia Aguiar Lopes Leandro. Icapuí/CE, 2013. 1(um) artigo. Rádio Gravador (76 min). 